\title{
Performance evaluation of herbaceous of bee forages for semi-arid parts of the rift valley of central, Ethiopia
}

\begin{abstract}
Availability of adequate nectar and pollen plant is the most limiting factor for honey production. The study was conducted with the objective of evaluating the performance of Echium plantaginium, Becium grandiflorum, Melilotus alba and Fagophyrum esculentum in semi-arid parts of rift valley of central Ethiopia. The species were evaluated based on flower heads per plants, foraging intensity of honeybees and duration of flowering. The mean time taken to set flower under rain fed condition for $F$. esculentum was about 38 days which is, the shortest of all plants. On contrary, the time taken to set flower after planting was 171 days for $B$. grandiflorum. The mean numbers of flower heads per plant were significantly higher $(\mathrm{p}<0.05)$ for $M$. alba under rain condition than irrigation, whereas similar for $F$. esculentum under both condition. The mean number of flower heads per plant was higher for E. plantaginium than other species, due to their growing habit and crown size. Honeybees foraging intensity and visiting time for different plant species were significantly different. Even though the plants species used in this experiment showed better performance under both condition, however further evaluation is required particularly on nectar yield potential of the plants. From these investigations, it is concluded that developing better performing plant species through use of irrigation and rain fed conditions will alleviate the shortage of honeybee forages and help in increasing honey production.
\end{abstract}

Keywords: bee forage, herbs, flowering period, pollen yield, foraging intensity
Volume 8 Issue 5 - 2018

\section{Tura Bareke,Admassu Addi}

Holeta Bee Research Center, Oromia Agricultural Research Institute, Ethiopia

\section{Correspondence: Tura Bareke, Holeta Bee Research Center, Oromia Agricultural Research Institute, Ethiopia} Email trbareke@gmail.com

Received: August 24, 2018 | Published: October 03, 2018

\section{Introduction}

Honeybee plants are those plant species that provide food source for honeybees. ${ }^{1,2}$ About $16 \%$ of the world's flowering plant species contribute to honeybees as food sources. ${ }^{3,4}$ Among the many flowering plants some of plant species supply both nectar and pollen abundantly and others provide nectar or pollen only. ${ }^{5}$ The diversity of flowering plants and their flowering duration differ from one place to other depending on variation in topography, climate and other cultural and farming practices. ${ }^{6}$ The extensive knowledge on type of plants, abundance, density and quality of bee flora resources are enabled beekeepers to utilize the resources efficiently at the maximum level. This would help to harvest a good yield of honey and other honeybee products in addition to effective pollination for better crop yields. ${ }^{2}$ Thus, the success of beekeeping primarily depends on availability and abundance of potential honeybee flora. ${ }^{7}$ Currently the scarcity of bee flora is a major limiting factor in development of the beekeeping in most parts of the country. The semi-arid rift valley region of Oromia is frequently affected by the recurrent droughts and deforestation and hence honeybees are facing serious food shortage during the dry period leading to colony absconding and loss of honey yield. As result the scarcity of bee forage, demand for dearth period bee flora is currently increasing from time to time from different stakeholders. Therefore to respond to the demand, it is necessary to identify and evaluate bee plants that adapt to the short and erratic rainfall conditions of the area that could improve the food base of the local honeybees colonies and significantly contribute to honey production. There are different species of plants that are identified as major source of honey and tolerant to semiarid climate of the Ethiopia. This includes $B$. grandiflorum that provides white honey in northern parts of the country; M. alba and F. esculentum (buckwheat) sources of golden honey in parts of the world. Since the honeybee forages have good merit, it is essential to evaluate their adaptability and potentiality for honey production in the semi-arid rift valley of East Shoa Zone of Oromia where the scarcity of the bee forage was the constraints' of beekeeping. Therefore, the objective of this study was to evaluate the adaptation and performance of the aforementioned honeybee forages in semi-arid agro- ecology of East Shoa Zone and identify the best performing honeybee forages that contribute to the production of honey and other bee products.

\section{Methods}

The study was carried-out at Alage Technical and Vocational Education Training College in Adami-Tullu Jido Kombolcha District of East Shoa Zone of Oromia Regional State. The site is located at an altitude of $2400 \mathrm{~m}$.a.s.1, at $09^{\circ} 03.5^{\top} \mathrm{N}$ latitude and $038^{\circ} 30.367^{`} \mathrm{E}$ longitudes.

\section{Bee forage plant selection and seed collection}

The bee forage plant species were selected on the basis of their potentiality for honey production and identified using published papers, field observation on foraging intensity of honeybees on flowers. In addition to this, this similarity of their growth habit, ease of propagation and multipurpose uses of the plant also considered. For this study, elite plants with mature seeds of E. plantaginium, M. alba, $F$. esculentum and $B$. grandiflorum were harvested with the whole branches. Immediately after harvesting, the branches with seeds were allowed to dry for a week around threshing place. Then the threshed seeds were packaged and maintained at room temperature until the day of sowing. 


\section{Experimental design}

To evaluate the performance of the selected plant materials, land was prepared according to required standards. Seeds were sown in row on prepared beds at the plot size of $2 \mathrm{~m} \times 2 \mathrm{~m}$ with seeding rate of $10 \mathrm{~kg} / \mathrm{ha}$ for M. alba and F. esculentum; $6 \mathrm{~kg} / \mathrm{ha}$ for E. plantaginium and $3 \mathrm{~kg} / \mathrm{ha}$ for $\mathrm{B}$. grandiflorum and the plots were arranged in randomized block design with three replications. To keep proper spacing and avoid nutrient competition, spacing used between the plants and rows were 20 and $30 \mathrm{~cm}$ respectively for all, except for B. grandiflorum which was $1 \mathrm{~m}$ for both. Seeds sown on the bed were covered with a thin layer of the same soil to protect seeds from birds and facilitate appropriate condition for germination. Fertilizer was not used to keep its natural growing state and planting was done both at rain fed and irrigation conditions. ${ }^{8}$ (Figure 1) Data collection was made on days to germinate, blooming time, number of flower heads per plant, foraging intensity of honeybees starting from 6:00 am to 6:00 pm for ten minutes at every 2 hours interval for ten days. Pollen yield of 50 matured flower heads having similar age was taken at $50 \%$ flowering of the species and pollen was kept for certain days to dry at room temperature and shaked on paper tray. Then, pollen was weighed using sensitive weighing balance. Flower blooming to shedding time and seed yield were also recorded for each treatment plants. Finally, the data were statistically analyzed using box plot and other descriptive statistical tools.
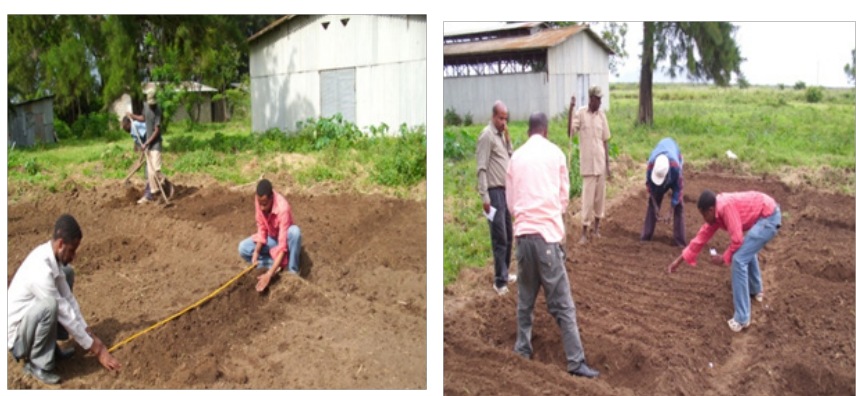

Figure I Land preparation for sowing.

\section{Results}

\section{Germination days}

The result indicated that germination date of M. alba was highly significant $(\mathrm{p}<0.05)$ under rain fed condition than irrigation; whereas the rest of the species showed similar days of germination under both conditions (Figure 2).

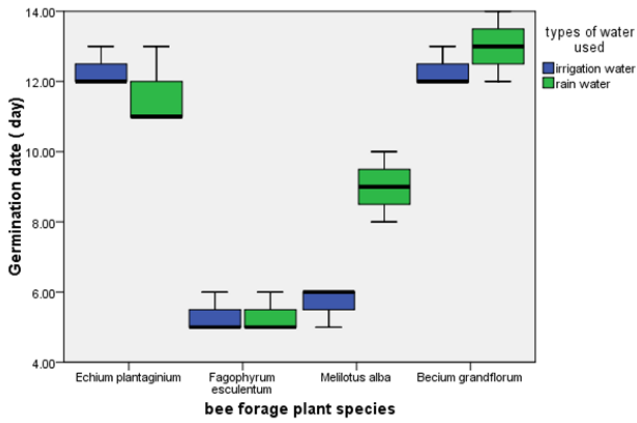

Figure 2 Germination date of E. plantaginium, B. grandiflorum, M. alba and $F$. Esculentum.

\section{Blooming date}

The mean blooming time of $M$. alba and F. esculentum were higher under rain fed than irrigation while E. plantaginium and $B$. grandiflorum were showed similar blooming time under both condition. The mean time taken to set flower under rain fed condition for $F$. esculentum was about 38 days which is, the shortest of all plants. On contrary, the time taken to set flower after planting was increased to 171 days for $B$. grandiflorum (Table 1).

Table I Blooming time (day) and pollen yield of 50 flower heads (gm.) of the following plant species under rain fed and irrigation

\begin{tabular}{lllll}
\hline Plant species & \multicolumn{2}{l}{ Blooming time } & \multicolumn{2}{l}{ Pollen yield } \\
\cline { 2 - 5 } & Rain fed & Irrigation & Rain fed & Irrigation \\
\hline E. plantaginium & $|4| .4$ & $14 \mid$ & 0.4 & 0.035 \\
F. esculentum & 38 & 31 & 0.24 & 0.018 \\
M. alba & 90 & 71.3 & 0.46 & 0.058 \\
B. grandiflorum & 172 & I7I & 0.005 & 0 \\
\hline
\end{tabular}

\section{Number of flower heads/plant}

The mean numbers of flower heads per plant were significantly higher $(\mathrm{p}<0.05)$ for $M$. alba under rain condition than irrigation, whereas similar for $F$. esculentum under both condition. The mean number of flower heads per plant was higher for E. plantaginium than other species, due to their growing habit and crown size. More branching produces more flower heads per plant (Figure 3).

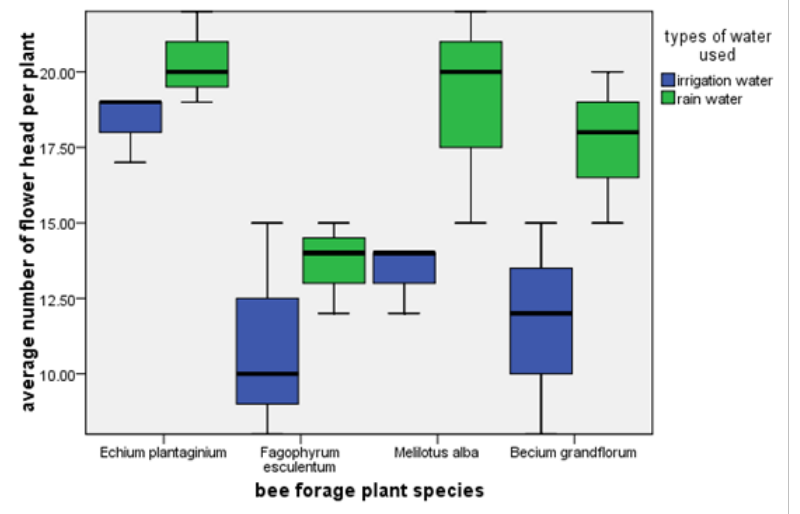

Figure 3 Number of flower heads per plant for E. plantaginium, B. grandiflorum, M. alba and F. esculentum.

\section{Pollen yield}

The pollen yield of $B$. grandiflorum was almost null under irrigation condition and significantly very low under rain condition as compared to other species. Thus the pollen yield of all species under study was similar under both conditions. However, under both rain fed $M$. alba was produced the highest pollen yield followed by $E$. plantaginium, F. esculentum and B. grandiflorum pollen yield was the lowest of all species (Table 1).

\section{Blooming to shedding (Flowering length)}

Flowering length of the plant species was similar for all species under both rain and irrigation condition. E. plantaginium has taken took longer flowering time while $F$. esculentum took the shortest flowering time (Figure 4). 


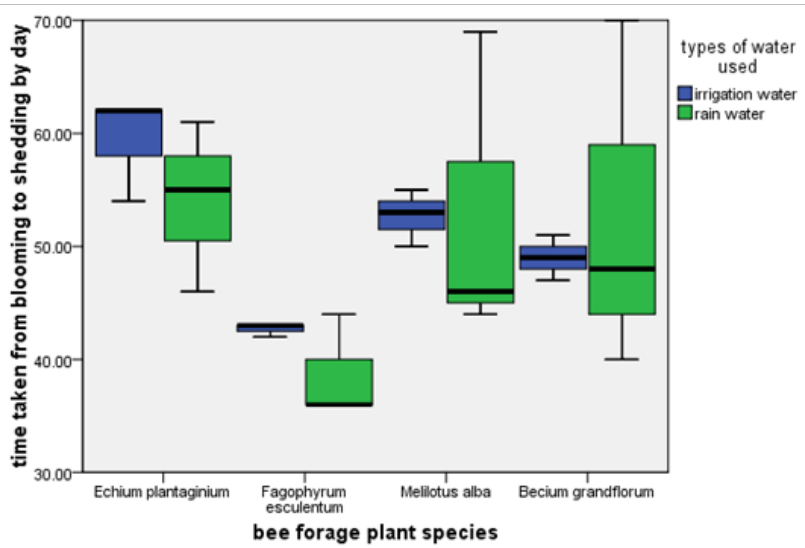

Figure 4 Time taken from blooming to shedding (day) for E. plantaginium, $B$. grandiflorum, M. alba and F. esculentum.

\section{Seed yield}

Under both rain fed and irrigation $M$. alba produced higher seed yield followed by $E$. plantaginium and $F$. esculentum, respectively. While B. grandiflorum was the lowest of all (Table 2).

Table 2 Average seed yield of in quintal/ha under rain fed and irrigation

\begin{tabular}{lll}
\hline Plant species & \multicolumn{2}{l}{ Average seed yield in quintal/ha } \\
\hline & Rain fed & Irrigation \\
\cline { 2 - 3 } E. plantaginium & 1.6 & 3.1 \\
F. esculentum & 0.5 & 1.5 \\
M. alba & 5.7 & 6.6 \\
B. grandiflorum & 0.125 & 0 \\
\hline
\end{tabular}

\section{Foraging intensity of honeybees}

The foraging intensity of honeybees on E. plantaginium was highly foraged by honeybees and followed by $B$. grandiflorum, $M$. alba and F. esculentum under rain fed (Figure 5). On the other hand B. grandiflorum was highly visited by honeybees and followed by $E$. plantaginium, $M$. alba and $F$. esculentum under irrigation condition (Figure 6). Peak honeybee foraging time was varied from species to species and season to season depending on attractiveness of the flower and weather condition.

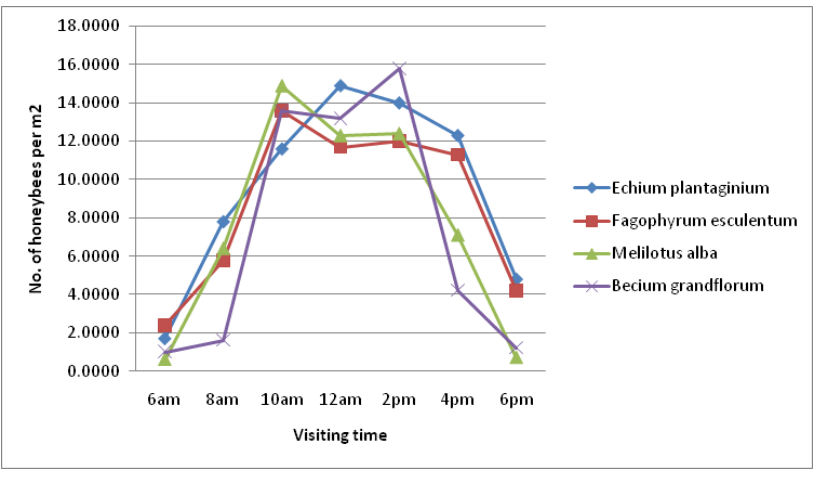

Figure 5 Foraging time and intensity of honeybees at different time of days on E. plantaginium, F. esculentum, M. alba and B. grandiflorum under rain fed.

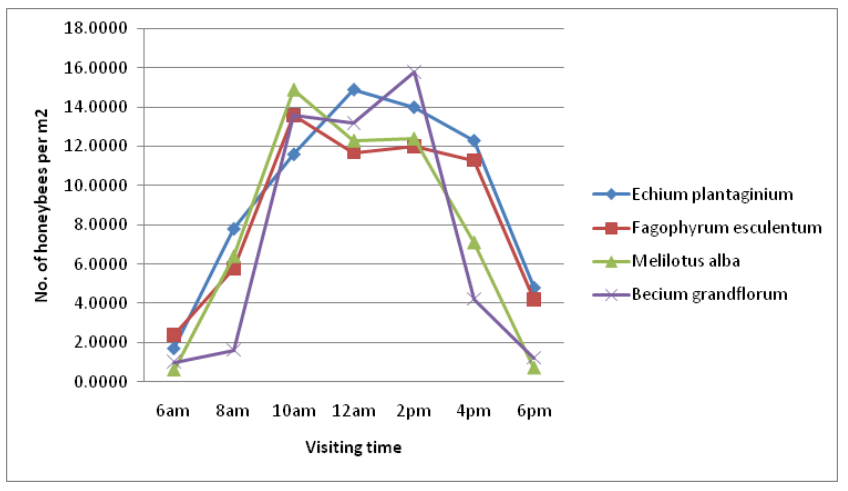

Figure 6 Foraging time and intensity of honeybees at different time of days on E. plantaginium, F. esculentum, M. alba and B. grandiflorum under irrigation.

\section{Discussion}

The analysis of germination performance of the species revealed that germination dates of the treatment species were varied between rain and irrigation condition. The germination date of $M$. alba was highly significant under rain fed than irrigation. This may be due to the variation of the temperature, soil condition and germination behavior of the plants in both seasons. This is in agreement with ${ }^{9}$ also reported that in the life cycles of plants germination and emergence of plants are the two most important factors that determine the efficient use of the nutrients and water resources available to plants. Temperature, light, $\mathrm{pH}$, and soil moisture are the important environmental factors that affect seed germination of the plants..$^{10}$ On the other hand, temperature and other environmental factors such as seed moisture and the nature of the stored food also affect the state of seed dormancy in most plants. ${ }^{11}$ The mean blooming time of $M$. alba and $F$. esculentum were higher under rain fed condition than irrigation. This is could be due to the adaptability of the plants to higher rainfall condition and other associated environmental factors such as length of sunny days and moisture in the soil. Availability of moisture in the soil also increases with the duration of flowering length and the foraging intensity of honeybees on the flower. ${ }^{8}$ It enhances the vegetative growth of a plant and it supports the plants that grow or stay longer and bigger in size and able to support more reproductive growth before flowering. ${ }^{12}$ In addition to this timing of reproductive events or phenology in many plants are changed strongly by photoperiod and temperature. Variation in time to flowering results from differences in sensitivity of genotypes to changes in photo-thermal regimes. This response affects adaptation to diverse environmental conditions. ${ }^{13}$

E. plantaginium provided higher number of flower heads per plant under rain and irrigation condition. This is due to their crown size and multiple branching habits of the plants resulting in more flower head production. Similar, study has been reported by ${ }^{8}$ E. plantaginium is one of the best bee forage plant that had higher number of flower heads per plant. This is supported by several studies indicating that bee forage plants with more flower heads are very important to provide ample nectar and pollen for honeybee colonies. Moreover, bee forage plants which have also long flowering period starting from blooming to shedding are highly preferred by honeybees for continues supply of nectar and pollen to boost honey production. Honeybees have a marked preference for one kind of plant species over the other, which may be equally abundant. This is due to diets of honeybees from the flowers consisting of the pollen and nectar from different plant species may have different nutritional value 
for the honeybees. ${ }^{3}$ E. plantaginium was highly visited under rain fed whereas $B$. grandiflorum under irrigation. The preference a of honeybee forage plants are associated with different factors such as attractiveness of the flower, number of flower heads per plants, nectar sugar concentration, yield and nutritive value pollen of plants and weather condition of the area. ${ }^{14}$ This is supported with ${ }^{3}$ also reported that the intensity of bee visit is a measure of potentiality of plants for nectar and pollen production. The foraging time of honeybees has varied from bee forage plant species to other species, and the peak foraging time ranged from 9 a.m-2p.m under irrigation whereas 10 a.m to $2 \mathrm{ppm}$ under rain fed. From this observations recorded on the foraging intensity of the honeybees showed that visiting honeybees were few in the early morning and late in the evening due the cold weather condition affecting the flight of honeybees. ${ }^{15}$ The foraging time of honeybee is varying from plant species to species based on nectar secretion time, volume and concentration and time of pollen release of plants.

\section{Conclusion and recommendations}

The study revealed that even though the number of flower heads per plant was different under rain and irrigation condition for each species, under this study, their flowering length and pollen yield was almost similar. E. plantaginium was highly visited under rain fed whereas $B$. grandiflorum under irrigation. The variation was seen in foraging intensity of honeybee for the same plant species under different season is due to variation of weather condition of the area and its adaption to different soil factors. Though the variation occurred on intensity of foraging in different season, all plant used considered for the study was highly foraged by honeybees. The time spent by honeybees for foraging of plant species is varied depending on the amount of nectar and pollen present in the flower. In addition to this the peak foraging time is associated with nectar and pollen potentiality of the plant. In conclusion all plant species were performed very well under both conditions. Therefore, planting of better performing plant species through use of irrigation and rain fed conditions will alleviate the shortage of bee forages in dearth periods and help to sustain honeybee colonies in increasing honey production. Even though the plants species used in this experiment showed better performance under both condition, it requires further evaluation particularly nectar secretion potential of plants under rain fed and irrigation.

\section{Acknowledgements}

The authors are thankful to Holeta Bee Research Center and Oromia Agricultural Research Institute for providing required facilities and logistics. Our sincere thanks are also to Alage Technical and Vocational Education Training College, for their inspiration and support in the implementation and follow-up of the research.

\section{Conflict of interest}

The authors declared there is no conflict of interest.

\section{References}

1. Admassu A, Kibebew W, Amssalu B, et al. Honeybee forages of Ethiopia. Addis Ababa: United Printers; 2014.

2. Fichtl R, Admasu A. Honey bee flora of Ethiopia. The National Herbarium, Addis Ababa University and Deutscher Entwicklungsdieenst, Mergaf Verlag, Germany; 1994. 510 p.

3. Crane E. Bees and beekeeping: science, practice and world resources. London: Heinnmann Newness; 1990. 614 p.

4. Adgaba N, Al-Ghamdi A, Tadesse Y, et al. Nectar secretion dynamics and honey production potentials of some major honey plants in Saudi Arabia. Saudi J Biol Sci. 2017;24(1):180-191.

5. Shubharani R, Sivaram V, Roopa P. Assessment of honey plants resources through pollen analysis in Coog honeys of Karnataka State. The International Journal of Plant Reproductive Biology. 2004;31-39.

6. Alemtsehay T. Seasonal availability of common bee flora in relation to land use and colony performance in Gergera watershed atsbi wembwrta district, eastern zone of Tigray, Ethiopia. MSc. Thesis, Debub University Wondo Genet College of Forestry Awassa, Ethiopia. 2011.

7. Baptist BA, Punchihewa RKW. A preliminary Analysis of the principal factors will affect honey production in Sri Lanka. In: Second International Conference on apiculture in Tropical climates. New Delhi; 1989. 98 p.

8. Tura BK, Kibebew WH, Admassu AM. Screening of Potential Herbaceous Honey Plants for Beekeeping Development. Agriculture, Forestry and Fisheries. 2014;3(5)386-391.

9. Gan Y, Elmer H Stobbe, Njue C. Evaluation of select nonlinear regression models in quantifying seedling emergence rate of spring wheat. Crop Sci. 1996;36(1):165-168

10. Rizzardi MA, Luiz AR, Roman ES, et al. Effect of cardinal temperature and water potential on morning glory (Ipomoea triloba) seed germination. Planta Daninha. 2009;27(1):13-21.

11. Pons TL. Seed responses to light. In: Fenner M, editor. Seeds: The ecology of regeneration in plant communities. New York: CAB International, 1993; 259-284 p.

12. John BA, Gordon RH, Parrish DJ. Plant Science. New York: McGraw-Hill publishing Company; 1987.

13. Adams MW, Coyne DP, Davis JHC, et al. Common bean (Phaseolus vulgaris L.). In: RJ Summerfield, et al. editors. Grain Legume Crops. London. 1985;433-476.

14. Debissa L, Admassu A, Amssalu B. Botanical inventory Phenology of bee plants in east shoa Zone. In ESAP proceedings, 2005.

15. Tura B, Admasu A, Kibebew W. Screening of Potential Shrubs for Bee Forage Development. Journal of Plant Sciences. 2017;5(5):160-164. 